\title{
AS TECNOLOGIAS DE INFORMAÇÃO E COMUNICAÇÃO COMO RECURSO PEDAGÓGICO NAS ESCOLAS MUNICIPAIS DO ENSINO REGULAR DE TAQUARA: recursos disponíveis e dificuldades identificadas ${ }^{1}$
}

\author{
Suzy de Abreu Costa \\ Universidade Aberta, Portugal \\ e-mail: suzydeabreucosta@gmail.com, Brasil \\ Filipa Seabra \\ LE@D, Universidade Aberta, Portugal; CIED-UMinho e CIPEM/INET-MD \\ e-mail: filipa.seabra@uab.pt, Portugal
}

\section{RESUMO}

Com o intuito de auxiliar com uma educação inclusiva, realizou-se um trabalho de investigação orientado à obtenção do doutorado que teve como objetivo geral, caracterizar o uso de tecnologias com vistas à inclusão, considerando a socialização, a aprendizagem, bem como, o respeito pelos direitos dos alunos com deficiências nas Escolas Municipais de Ensino Regular do Município de Taquara. A metodologia utilizada foi de cunho quanti-qualitativo, com o objetivo de obter-se uma maior compreensão dos fenômenos a serem investigados, tendo como técnicas de recolha de dados, inquérito por questionário e entrevista semiestruturada, instrumentos dirigidos, primeiramente à diretora da Secretaria de Educação Especial e, posteriormente, aos professores titulares e os de apoio. Nas análises dos resultados e durante o processo conclusivo, fez-se uma correlação com os objetivos específicos desta investigação, sendo estes: caracterizar os recursos tecnológicos e humanos disponíveis nas escolas para o atendimento aos estudantes com deficiência; conhecer as percepções dos professores titulares e os de apoio relativamente ao seu nível de competência na utilização destes recursos tecnológicos; analisar as perspectivas dos vários intervenientes sobre os impactos da utilização das TIC durante o processo de ensino e aprendizagem nos alunos especiais incluindo ao nível pedagógico, curricular e extracurricular; e, por último, analisar as perspectivas dos vários intervenientes sobre as limitações dos recursos existentes e entraves à sua efetiva utilização. Em particular, no presente texto, propomo-nos responder preliminarmente ao primeiro e último desses objetivos específicos.

Palavras-chave: Inclusão. Tecnologias de Informação e de Comunicação (TIC). Formação.

\footnotetext{
${ }^{1}$ O presente artigo retoma, com ligeiras alterações, o texto de uma comunicação apresentada no VII Simpósio de Educação Inclusiva e Adaptações/ V Simpósio Internacional de Educação a Distância. Tema: Práticas Inclusivas e Inovações: Os desafios da educação no séc. XXI, São Paulo, UNESP, 2019, o qual foi publicado no livro de atas do mesmo encontro.
} 


\title{
INFORMATION AND COMMUNICATION TECHNOLOGIES AS A PEDAGOGICAL RESOURCE IN MUNICIPAL SCHOOLS IN TAQUARA REGULAR EDUCATION: available resources and identified difficulties
}

\begin{abstract}
In order to assist with an inclusive education, a research work was carried out to obtaining a doctorate, whose general objective was to characterize the use of technologies with a view to inclusion, considering socialization, learning, as well as respect for the rights of students with disabilities in the Municipal Schools of Regular Education in the Municipality of Taquara. The methodology used was of a quanti-qualitative nature, with the objective of obtaining a greater understanding of the phenomenon to be investigated, having as techniques of data collection, inquiry by questionnaire and semi-structured interview. These techniques were directed, firstly to the director of the Secretariat of Special Education and, later, to classroom teachers and supporting teachers. In the analysis of the results and during the conclusive process, a correlation was made with the specific objectives of this investigation, which are: to characterize the technological and human resources available in schools to assist students with disabilities; to know the perceptions of teachers and support teachers regarding their level of competence in the use of these technological resources; to analyze the perspectives of the various stakeholders on the impacts of the use of ICT during the teaching and learning process on special students, including at the pedagogical, curricular and extracurricular level; and finally to analyze the perspectives of the various stakeholders on the limitations of existing resources and barriers to their effective use. In particular, this paper proposes to respond, preliminarily, to the first and last of these specific objectives.
\end{abstract}

Keywords: Inclusion. Information and Communication Technologies (ICT). Training.

\section{TECNOLOGÍAS DE INFORMACIÓN Y COMUNICACIÓN COMO RECURSO PEDAGÓGICO EN LAS ESCUELAS MUNICIPALES DE TAQUARA DE EDUCACIÓN REGULAR: recursos disponibles y dificultades identificadas}

\section{RESUMEN}

Para ayudar con una educación inclusiva, se llevó a cabo un trabajo de investigación para obtener un doctorado, cuyo objetivo general era caracterizar el uso de tecnologías con miras a la inclusión, considerando la socialización, el aprendizaje y el respeto por los derechos de los estudiantes con discapacidades en las Escuelas Municipales de Educación Regular en el Municipio de Taquara. La metodología utilizada fue de 
naturaleza cuanti-cualitativa, con el objetivo de obtener una mayor comprensión de los fenómenos a investigar, teniendo como técnicas de recolección de datos, consulta de cuestionarios y entrevistas semiestructuradas, instrumentos dirigidos, en primer lugar al director de la Secretaría de Educación especial y, más tarde, a los docentes completos y de apoyo. En el análisis de los resultados y durante el proceso concluyente, se realizó una correlación con los objetivos específicos de esta investigación, que son: caracterizar los recursos tecnológicos y humanos disponibles en las escuelas para ayudar a los estudiantes con discapacidades; conocer las percepciones de los profesores y profesores de apoyo con respecto a su nivel de competencia en el uso de estos recursos tecnológicos; analizar las perspectivas de los diversos interesados sobre los impactos del uso de las TIC durante el proceso de enseñanza y aprendizaje en estudiantes especiales, incluso a nivel pedagógico, curricular y extracurricular; y, finalmente, analizar las perspectivas de los diversos interesados sobre las limitaciones de los recursos existentes y las barreras para su uso efectivo. En particular, en este texto, proponemos responder preliminarmente al primero y al último de estos objetivos específicos.

Palabras clave: Inclusión. Tecnologías de la información y la comunicación (TIC). Formación.

\section{INTRODUÇÃO}

Desde a Declaração Universal dos Direitos Humanos de $1948^{2}$, a qual garante educação para todos, independentemente de origem, condição social, observando que cada indivíduo tem o direito de igualdade de oportunidades, perpassando-se quatro décadas, pela Unicef, na Convenção dos Direitos da Criança, em 1989³, ficam explicitados, também os direitos das pessoas com deficiências no ensino regular.

Porém, mesmo com todo o empenho de sociedades, de governos e professores, a inclusão das pessoas deficientes não ocorre de forma fácil. Muitos são os estudos que denotam as dificuldades no sistema de ensino, como, Rodrigues (2007); Ribeiro (2012); Gonçalves (2013); Casarin (2014); Tavares, (2014); e, Teles (2015), desde o processo inicial voltado a infraestrutura dos espaços físicos, na capacitação de professores, nos recursos pedagógicos facilitadores, na formulação de um projeto político pedagógico que contemple as diferenças, como também, na sensibilização da comunidade escolar em relação ao processo inclusivo.

Para Mendes (2015), diante dos desafios dos tempos atuais, cada vez mais observa-se nos cenários das práticas curriculares, a necessidade de adaptar-

\footnotetext{
${ }^{2}$ unesdoc.unesco.org/images/0013/001394/139423por.pdf

${ }^{3} \mathrm{http} / / / \mathrm{www}$.unicef.org/brazil/pt/resources_10120.htm.
} 
se novas estratégias pedagógicas, ao mesmo tempo em que o autor enfatiza que o conhecimento deverá ser sempre a principal meta no cenário educacional, pois o uso das tecnologias de informação e comunicação devem servir como uma ferramenta facilitadora, tendo-se o cuidado de adequar a estes recursos aos conteúdos curriculares,

(...) a inserção de computadores, bem como qualquer outra inserção que se deseja operar no cotidiano escolar deve necessariamente ser associado a uma reflexão crítica sobre os principais fundamentos do currículo e as mudanças na formação de professores (MENDES, 2015, p. 10).

Indo a favor destas necessidades, surgia a tecnologia assistiva visando propor e promover o acesso para pessoas com limitações funcionais nas escolas, com recursos facilitadores à comunicação, a promoção da independência e a inclusão nos espaços educacionais, o que é confirmado por Monteiro da Cruz e Monteiro (2013, p.10): "nos dias atuais, as tecnologias estão presentes em quase todos os aspectos da vida cotidiana, inclusive na escola".

Por reconhecer a necessidade de implementação dos recursos tecnológicos facilitadores ao processo inclusivo nos ambientes educacionais, o Ministério de Educação e Cultura (MEC), cria em 2013, o Plano Nacional dos Direitos da Pessoa com Deficiência Viver sem Limite, inserido no Programa Nacional de Inovação em TecnologiaAssistiva (PNIT), implementado pelo Ministério de Comunicação, Tecnologia e Informação-MCTI e pela Financiadora de Estudos e Projetos-Finep, tendo como objetivo, apoiar o desenvolvimento de produtos, metodologias, estratégias, práticas e serviços inovadores que aumentem a autonomia, o bem-estar e a qualidade de vida de pessoas com deficiência, conforme é reforçado na citação:

O Programa Escola Acessível disponibiliza recursos financeiros às escolas públicas, por meio do Programa Dinheiro Direto na Escola, para promoção de acessibilidade arquitetônica nos prédios escolares e compra de materiais e equipamentos de tecnologia assistiva (PNIT, 2013, p. 16).

Em virtude destes meios de comunicação e de aprendizagem terem o amparo da legislação brasileira nos ambientes escolares, e por estes recursos estarem se tornando, de forma crescente, importantes instrumentos de acessibilidade, o que se pretende através desta pesquisa, além do processo investigativo quanto a capacitação dos educadores e da caracterização das TICs, é a promoção da inclusão social, amenizando as barreiras quanto ao aprendizado às pessoas com deficiências (PCD), possibilitando uma condição equânime de justiça social, diminuindo preconceitos, reforçando habilidades, desenvolvendo potencialidades e melhorando a autoestima destes indivíduos (LEVY, 1999). 


\section{OBJETIVOS}

O objetivo geral do trabalho realizado foi de caracterizar o uso de tecnologias com vista à inclusão dos alunos com deficiências nas Escolas Municipais de Ensino Regular do Município de Taquara.

Com vista à obtenção desse objetivo, delinearam-se objetivos específicos entre os quais se contam:

2.1 Fazer o levantamento dos recursos tecnológicos disponíveis nas Escolas Municipais de Ensino Regular do Município de Taquara para o atendimento aos estudantes com deficiência;

2.2 Conhecer as percepções dos professores titulares e os de apoio relativamente ao seu nível de competência na utilização destes recursos tecnológicos;

2.3 Analisar na perspectiva dos professores titulares e os de apoio a utilização que é feita destas tecnologias no contexto do ensino-aprendizagem;

2.4 Conhecer as perspectivas dos professores titulares e os de apoio sobre os benefícios pedagógicos, curriculares e extracurriculares resultantes da utilização destas tecnologias; e,

2.5 Analisar as perspectivas dos vários intervenientes sobre as limitações dos recursos existentes e entraves à sua efetiva utilização.

\section{FUNDAMENTAÇÃO}

O papel da TIC no cenário educacional vem adquirindo cada vez mais relevância. Sua utilização dentro do processo de ensino-aprendizagem vem aumentando de uma forma muito significativa, ocasionando mudanças sociais, estruturais e funcionais frente à comunidade escolar, sendo estes recursos reconhecidos pela UNICEF (2012, p.74):

(...) salas de recurso podem ser fornecidas estando equipadas com a tecnologia e ferramentas, sendo geridas por especialistas experientes em técnicas de ensino colaborativo e pode oferecer suporte a crianças e professores nas salas de aula tradicionais. (...) computadores e tecnologias de informação e comunicação (TIC) de tecnologias podem ser um benefício significativo para as crianças com deficiência e facilitar a aprendizagem flexível. Para muitas crianças, a comunicação muitas vezes pode ser difícil e TIC permitem maior interação com as pessoas em seu ambiente imediato e promovem a comunicação, interação, cognição e aprendizagem. Usar computadores e tecnologia assistiva relacionada em atividades educativas ajuda as crianças a ganhar autoconfiança, habilidades sociais, habilidades de comunicação, habilidades motoras brutas e fina, habilidades e uma ampla gama de habilidades e conhecimentos necessários para resolver problemas diante da sociedade ${ }^{4}$.

\footnotetext{
${ }^{4}$ Approach to Inclusive Education. Geneva: UNICEF Regional Office for Central and Eastern (2012). The Right of Children with Disabilities to Education: A Rights-Based A Europe and the Commonwealth of Independent States (CEECIS).Disponível em: https://www.unicef.org/disabilities/files/UNICEF_Right_to_Education_Children_Disabilities_En_Web.pdf.
} 
Visando a evolução do processo educativo de qualidade, entretanto, conforme Marchesi e Martin (1995), é necessário ainda a abordagem de como o profissional deve lidar com situações de diversidades, ressaltando a importância de se incluir a aprendizagem de habilidades, inserindo estratégias de planejamento, tais como, programações específicas, adaptações no currículo, metodologia, organização da classe, avaliação, técnicas de trabalho em grupo, estratégias de intervenção em função das dificuldades de aprendizagem do educando, reforçando que:

A formação do professor deve ser continuada, para que vise a diversidade e tenha facilidade em lidar com a mudança, sempre pronto a inovar suas práticas pedagógicas. Para isso é preciso que se tenha uma boa formação de base, inicial, e formação continuada (MARCHESI; MARTIN,1995, p. 97).

Neste sentido, por não haverem estudos científicos comprobatórios da utilização destas tecnologias nas Escolas Regulares Municipais de Ensino Fundamental da cidade de Taquara- Rio Grande do Sul (Brasil) e, tomando como relevância o Parecer $n^{\circ} 17 / 2001^{5}$ do Conselho Nacional de Educação (CNE), esta pesquisa investigativa de cunho interpretativo, e recorrendo a uma metodologia quantitativa e qualitativa procurou-se fazer os seguintes levantamentos: os recursos tecnológicos disponíveis nas Escolas Municipais de Ensino Regular do Município de Taquara para o atendimento aos estudantes com deficiência; as percepções, os entraves e as perspectivas dos professores relativamente ao seu nível de competência na utilização destes recursos e de seus benefícios pedagógicos, curriculares e extracurriculares nos alunos.

\section{METODOLOGIA}

De caráter interpretativo, este projeto englobou os aspectos qualitativos e quantitativos dos fenômenos analisados no campo de pesquisa, na medida em que se "tem o objetivo de considerar pontos de vista e perspectivas múltiplas" (MORAIS; NEVES, 2007), considerando os sujeitos e as correlações com os objetivos do investigador, buscando o conhecimento ideográfico, bem como as análises das intenções comportamentais e educativas dos participantes, preconizando o respeito por parte do investigador durante todas as fases da pesquisa.

Após validação e autorização superior, foi realizada uma entrevista semiestruturada com a Diretora de Educação Especial, professores titulares e de apoio; e aplicado um questionário aplicado aos educadores envolvidos na pesquisa, sendo ainda realizada uma pesquisa documental.

\footnotetext{
${ }^{5}$ Ministério de Educação e Cultura (2001). Parecer CNE/ CEB 17/2001. Despacho do Ministro em 15/08/2001, publicado no Diário Oficial da União de 17/08/2001, seção 1, p. 46. Disponível em: http:// portal.mec.gov.br/seesp/arquivos/pdf/parecer17.pdf.
} 


\subsection{Design Metodológico}

Esta pesquisa foi relacionada com um estudo de natureza mista, mas eminentemente qualitativo, de natureza descritiva e interpretativa, considerando o design metodológico abaixo (Quadro 01), estando inserido com os objetivos do projeto, relacionando as técnicas de recolha de dados (entrevista semiestruturada e inquérito por questionário); as fontes (Diretora da Educação Especial do Município de Taquara e professores titulares e os de apoio); e com as técnicas de análise de dados (documental, estatística e de conteúdo):

Quadro 1 - Design metodológico do estudo.

\begin{tabular}{|c|c|c|c|}
\hline Objetivos & $\begin{array}{l}\text { Técnicas de recolha } \\
\text { de dados }\end{array}$ & Fontes & $\begin{array}{l}\text { Técnicas de análise } \\
\text { de dados }\end{array}$ \\
\hline $\begin{array}{l}\text { Fazer o levantamento } \\
\text { dos recursos } \\
\text { tecnológicos disponíveis } \\
\text { nas Escolas Municipais } \\
\text { de Ensino Regular do } \\
\text { Município de Taquara } \\
\text { para o atendimento } \\
\text { aos estudantes com } \\
\text { deficiência. }\end{array}$ & $\begin{array}{l}\text { Entrevista } \\
\text { Semiestruturada } \\
\text { Recolha } \\
\text { documental } \\
\text { Entrevista } \\
\text { Semiestruturada } \\
\text { Inquérito por } \\
\text { Questionário }\end{array}$ & $\begin{array}{l}\text { Diretor da Secretaria da } \\
\text { Educação Especial. } \\
\text { Dados referentes aos } \\
\text { recursos tecnológicos } \\
\text { Professores Titulares e } \\
\text { Professores de Apoio } \\
\text { das Escolas da rede } \\
\text { municipal (10 de cada). } \\
\text { Professores Titulares e } \\
\text { Professores de Apoio } \\
\text { das Escolas da rede } \\
\text { municipal (153). }\end{array}$ & $\begin{array}{l}\text { Análise de } \\
\text { conteúdo } \\
\text { Análise de } \\
\text { conteúdo } \\
\text { Análise de } \\
\text { conteúdo } \\
\text { Análise } \\
\text { estatística }\end{array}$ \\
\hline $\begin{array}{l}\text { Conhecer as percepções } \\
\text { dos professores } \\
\text { titulares e os de apoio } \\
\text { relativamente ao seu } \\
\text { nível de competência } \\
\text { na utilização destes } \\
\text { recursos tecnológicos. }\end{array}$ & $\begin{array}{l}\text { Inquérito por } \\
\text { questionário } \\
\text { Entrevista } \\
\text { semiestruturada }\end{array}$ & $\begin{array}{l}\text { Aos } 153 \text { Professores } \\
\text { titulares e de os } \\
\text { apoios dos alunos } \\
\text { com deficiência que } \\
\text { frequentam as escolas } \\
\text { municipais. } \\
\text { Aos } 20 \text { professores, } \\
\text { sendo } 10 \text { titulares e } 10 \\
\text { de apoios: critérios de } \\
\text { seleção - } 4 \text { professores } \\
\text { de crianças com } \\
\text { cada um dos tipos de } \\
\text { deficiência (deficiência } \\
\text { auditiva, deficiência } \\
\text { visual, deficiência } \\
\text { motora, deficiência } \\
\text { mental, múltipla), } \\
\text { considerando cada uma } \\
\text { das séries do ensino } \\
\text { fundamental (iniciais e } \\
\text { finais). }\end{array}$ & $\begin{array}{l}\text { Análise } \\
\text { estatística }\end{array}$ \\
\hline
\end{tabular}


Continua

\begin{tabular}{|c|c|c|c|}
\hline Objetivos & $\begin{array}{l}\text { Técnicas de recolha } \\
\text { de dados }\end{array}$ & Fontes & $\begin{array}{l}\text { Técnicas de análise } \\
\text { de dados }\end{array}$ \\
\hline $\begin{array}{l}\text { Analisar, na perspectiva } \\
\text { dos professores } \\
\text { titulares e os de apoio, } \\
\text { a utilização que é feita } \\
\text { destas tecnologias no } \\
\text { contexto do ensino- } \\
\text { aprendizagem. }\end{array}$ & $\begin{array}{l}\text { Inquérito por } \\
\text { questionário }\end{array}$ & $\begin{array}{l}\text { Aos } 153 \text { professores } \\
\text { titulares e os de apoio } \\
\text { com alunos que } \\
\text { apresentem deficiência } \\
\text { e que frequentam as } \\
\text { escolas municipais. }\end{array}$ & $\begin{array}{l}\text { Análise } \\
\text { estatística }\end{array}$ \\
\hline $\begin{array}{l}\text { Conhecer as } \\
\text { perspectivas dos } \\
\text { professores titulares e } \\
\text { os de apoio sobre os } \\
\text { benefícios pedagógicos, } \\
\text { curriculares e } \\
\text { extracurriculares } \\
\text { resultantes da utilização } \\
\text { destas tecnologias. } \\
\text { Analisar as perspectivas } \\
\text { dos vários intervenientes } \\
\text { sobre as limitações dos } \\
\text { recursos existentes e } \\
\text { entraves à sua efetiva } \\
\text { utilização. }\end{array}$ & $\begin{array}{l}\text { Entrevista } \\
\text { semiestruturada }\end{array}$ & $\begin{array}{l}\text { Aos } 20 \text { professores, } \\
\text { sendo } 10 \text { titulares e } 10 \\
\text { de apoios: } \\
\text { critérios de seleção - } 4 \\
\text { professores com alunos, } \\
\text { sendo cada um dos } \\
\text { tipos de deficiência } \\
\text { (deficiência auditiva, } \\
\text { deficiência visual, } \\
\text { deficiência motora, } \\
\text { deficiência mental, } \\
\text { múltipla), considerando } \\
\text { cada uma das } \\
\text { séries do ensino } \\
\text { fundamental (iniciais e } \\
\text { finais). } \\
\text { Diretor da Secretaria da } \\
\text { Educação Especial }\end{array}$ & Análise de conteúdo \\
\hline
\end{tabular}

Fonte: Autoria própria, 2020.

\section{RESULTADOS E DISCUSSÃO}

Considerando a recolha de documentos e entrevista semiestruturada realizada com a Diretora de Educação Especial da Secretaria de Educação, Cultura e Esportes do Município de Taquara; o questionário respondidos pelas 143 (cento e quarenta e três) educadores ${ }^{6}$ atuantes na docência inclusiva das Escolas de Ensino Fundamental do Município; e, pelas entrevistas semiestruturas realizadas pelos 16 (dezesseis) educadores ${ }^{7}$, chegou-se aos seguintes resultados, dos quais serão descritos nos próximos subitens.

\footnotetext{
${ }^{6}$ Ressalta-se que 10 (dez) educadores não demonstraram interesse em participar da enquete, visto o levantamento inicial de 153 (cento e cinquenta e três) por parte da diretora, no momento da entrevista. ${ }^{7}$ Sendo 08 (oito) titulares e 08 (oito) de apoio, considerando os alunos, dois com deficiência motora; dois com deficiência mental; dois com deficiência visual; dois com deficiência múltipla (cada um deste dois alunos com deficiência, um estaria a frequentar a série inicial e o outro, a série final do Ensino fundamental, relembrando que a proposta inicial desta pesquisa era também vincular dois alunos com deficiência auditiva, porém, por não ter havido matrícula nas séries iniciais do Ensino Fundamental com deficiência visual no ano corrente a esta investigação, não foram realizadas as entrevistas semiestruturadas com os professores, titular e de apoio em nenhuma das séries.
} 


\subsection{Análise dos recursos tecnológicos disponíveis nas Escolas Municipais de Ensino Regular do Município de Taquara com vista à inclusão das pessoas com deficiência}

Através das análises, percebeu-se o quanto encontra-se carente o acesso às TICs em sala de aula, conforme pode-se constatar na tabela abaixo, relacionada aos recursos materiais, onde as respostas do questionário do subitens 04 e 13, são em ambos os casos no sentido da discordância; os professores consideram não ter ao seu dispor recursos suficientes para usar as TICs com os seus alunos com deficiência (Q.4; Média 2,03; D.P. = 1,22), e não consideram adequados os recursos ao seu dispor (Q. 13, Média 2,12; D.P.= 1,23).

Tabela 1 relacionada aos subitens 04 e 13 da questão 08 do questionário aplicado aos professores.

\begin{tabular}{l|l|l|l}
\hline $\begin{array}{l}\text { Subitens da questão 08 referentes } \\
\text { aos recursos materiais }\end{array}$ & $\begin{array}{l}\text { Média } \\
\text { Desvio } \\
\text { Padrão }\end{array}$ & $\begin{array}{l}\text { Número de } \\
\text { respostas } \\
\text { válidas }\end{array}$ & $\begin{array}{l}\text { Interpretação } \\
\text { (Escala Likert) }\end{array}$ \\
\hline $\begin{array}{l}\text { 04. Considero suficientes os recursos } \\
\text { ao meu dispor para poder usar as } \\
\text { TICs com os meus alunos com } \\
\text { deficiência. }\end{array}$ & $\begin{array}{l}2,03 ; \\
1,22\end{array}$ & 133 & Discordância \\
\hline $\begin{array}{l}\text { 13. Os recursos tecnológicos ao meu } \\
\text { dispor para trabalhar com alunos com } \\
\text { deficiência são adequados }\end{array}$ & 2,$12 ;$ & 124 & Discordância \\
\hline
\end{tabular}

Fonte: Dados da Pesquisa.

Apesar de haver a presença do professor de apoio para com as diferentes deficiências, o material pedagógico utilizado, na grande maioria, ainda é o tradicional, dificultando em uma aprendizagem significativa para estes alunos, pois na elucidação de Jonassen (2007), o uso de tecnologia em ambientes educativos é considerado uma ferramenta cognitiva; uma estratégia significante no processo de aprendizagem, servindo como um complemento didático no favorecimento ao conhecimento, dando vistas ao desenvolvimento integral do indivíduo.

\subsection{Análise das perspectivas dos vários intervenientes sobre as limitações dos recursos existentes e entraves à sua efetiva utilização}

Ficou evidenciado na pesquisa que as limitações e os entraves principais estão vinculados a uma maior formação dos educadores, tanto titulares, como os de apoio, sejam das séries iniciais, como as finais, nos conteúdos voltados ao processo 
inclusivo e da necessidade de terem recursos tecnológicos em sala de aula, conforme ilustra a tabela abaixo, relacionada as questões 01 e 02 do questionário:

Tabela 2 relacionada aos subitens 01 e 02 da questão 08 do questionário aplicado aos professores.

\begin{tabular}{l|l|l|l}
\hline $\begin{array}{l}\text { Subitens da questão } 08 \text { referentes à } \\
\text { percepção de competência no uso } \\
\text { das TICs }\end{array}$ & $\begin{array}{l}\text { Média e } \\
\text { Desvio } \\
\text { Padrão }\end{array}$ & $\begin{array}{l}\text { Número de } \\
\text { respostas } \\
\text { válidas }\end{array}$ & $\begin{array}{l}\text { Interpretação } \\
\text { (Escala Likert) }\end{array}$ \\
\hline $\begin{array}{l}\text { 1. Sinto-me suficientemente } \\
\text { capacitado (a) para usar as TICs com } \\
\text { os meus alunos com deficiência. }\end{array}$ & $\begin{array}{l}2,63 ; \\
1,29\end{array}$ & 134 & Discordância \\
\hline $\begin{array}{l}\text { 2. Necessito de maior formação para } \\
\text { usar as TICs com os meus alunos } \\
\text { com deficiência. }\end{array}$ & $\begin{array}{l}4,17 ; \\
1,33\end{array}$ & 137 & Concordância \\
\hline
\end{tabular}

Fonte: Dados da Pesquisa.

Em se tratando de 143 professores investigados, os números apresentados reforçam a necessidade de formação ao uso das tecnologias de informação e comunicação, pois sabe-se o papel significativo do uso destes recursos no processo de aprendizagem, na socialização, na independência e na autoestima dos alunos, o que faria valer às legislações vigentes.

\subsection{Análise dos benefícios do uso das TICs no processo de aprendizagem dos alunos especiais}

Analisando-se os três grupos de informações: entrevistas realizadas com a diretora, professores de alunos com deficiência (titulares e de apoio) e os questionários, chegou-se à conclusão que poucos educadores têm formação e/ou competência ao uso das TICs, como também, poucos têm acesso aos recursos tecnológicos, visto estes materiais estarem inseridos nas salas de recursos.

Da mesma forma, ficou definido no processo investigativo, que há uma expectativa dos educadores que tais recursos seriam significativos como instrumentos estratégicos facilitadores na prática pedagógica inclusiva, tendo como resultante uma aprendizagem significativa nos conteúdos curriculares e extracurriculares, com uma maior possibilidade de promoção, bem como, uma melhora na autoestima, na autonomia, na interação social e comunicação, pois sabe-se que o educador tem como função primordial, mostrar ao aluno o sentido do conhecimento, sendo o seu papel, uma parte significativa no processo de aprendizado, e que o uso da informática no espaço escolar deve funcionar como mais um recursos na construção das 
diferentes ciências, baseando-se em epistemologias que priorizem a ação do sujeito (JONASSEN, 2007).

\section{CONSIDERAÇÕES FINAIS}

Na apresentação dos dados com as análises, de conteúdo, documental, estatística e na discussão de resultados, feitas através dos documentos coletados, dos questionários aplicados, das entrevistas semiestruturadas e suas triangulações, conforme as variantes levantadas e as questões norteadores desta investigação, conclui-se que os recursos tecnológicos disponíveis nas Escolas Municipais de Ensino Regular do Município de Taquara com vista à inclusão das pessoas com deficiência e a percepção dos professores relativamente ao seu nível de competência na utilização das TICs, obtiveram um resultado indesejável, considerando o número de alunos especiais matriculados nas escolas, como constatou-se na discussão de dados.

Referente aos recursos tecnológicos, principalmente nos ambientes de sala de aula, conclui-se que há pouco material disponível, verificação também analisada no estudo de arte, na pesquisa de Tavares (2014) e de Rodrigues (2007), ao referirem-se da dificuldade de os educadores terem acesso às TICs por diversos motivos, entre eles o financeiro. Outrossim, constatou-se, nas análises documental e na entrevista com a diretora, que há uma sensibilização e um comprometimento por parte do Governo Municipal em capacitar cada vez mais e continuamente, um número maior de educadores nos conteúdos inclusivos, introduzir uma quantidade maior de recursos tecnológicos em todas salas de recursos das escolas faltantes, como também, a posteriori, em todas as salas das escolas municipais, apesar de estarem conscientes do impasse existente do recebimento de verba federal, havendo uma lentidão no processo final de concretização deste apoio financeiro pós- projetos, conforme relato da diretora.

Acredita-se que os educadores de apoio, como também, todos os titulares, deveriam estar melhores amparados, principalmente no está preconizado no parecer de número 17/2001 do CNE, citado na introdução deste trabalho, pois além da reforçar a necessidade de uma formação inclusiva inicial e contínua, reitera a competência ao uso das tecnologias na educação especial, sendo esta legislação federal, o elo norteador de análise de todo este processo investigativo, no sentido de tomada de conhecimento dos direitos das pessoas com deficiências.

Da mesma forma, há uma distância na prática pedagógica do uso das TICs, conforme o que determina a resolução do Conselho Nacional de Educação-CNE/CP de 18 de fevereiro de 2002, artigo 2, itens V, VI e VII, mesmo terem se passados 20 (vinte) anos, quando foi proferido: 
[...] é aconselhável ainda a elaboração e execução de projetos de desenvolvimento de conteúdos curriculares; o uso da tecnologia da informação e da comunicação e de metodologias, estratégias e materiais de apoio inovadores; e desenvolvimento de hábitos de colaboração e do trabalho em equipe.

Tem-se ciência da necessidade de ter-se uma escola para todos, conforme Slee (2012) elucida ao descrever quanto ao tipo de instituição que deve ser ofertada aos novos alunos diante do cenário diversificado, preconizando não somente a infraestrutura, mas também, a capacitação dos recursos humanos, a construção de um projeto político pedagógico capaz de favorecer a inclusão e a sensibilização de toda uma comunidade:

Precisamos estar nos perguntando que tipo de instalações escolares são necessários para todas as crianças neste século que irá construir o conhecimento, habilidades e disposição para trabalhar e remodelar o mundo do futuro? (...) Temos tudo a ganhar com a autêntica representação da diversidade. As melhorias necessárias no currículo, a pedagogia e a avaliação, projeto de escola e o estabelecimento do envolvimento das comunidades é bom para todos os alunos e educadores (SLEE, 2012, p. 11).

Já no término do seu prazo, tem-se no Brasil a regulamentação que orientaria a Educação Especial através do Plano Nacional de Educação-PNE (2011-2020) ${ }^{8}$, que deveria abranger todos os educandos deficientes, através de propostas inclusivas em todas as modalidades de ensinos, básica à superior, sendo que cada instituição de ensino deveria constar com o AEE, disponibilizando serviços e recursos adequados às necessidades dos educandos e professores, em turmas, preferencialmente, no ensino regular, conforme descreve a Meta 04 desta normativa:

Meta 4: universalizar, para a população de 4 (quatro) a 17 (dezessete) anos com deficiência, transtornos globais do desenvolvimento e altas habilidades ou superdotação, o acesso à educação básica e ao atendimento educacional especializado, preferencialmente na rede regular de ensino, com a garantia de sistema educacional inclusivo, de salas de recursos multifuncionais, lasses, escolas ou serviços especializados, públicos ou conveniados.

Porém, infelizmente, ficou constatado nesta pesquisa que esta prerrogativa inclusiva ainda não funciona com equidade nos espaços escolares investigados e que, certamente, os resultados negativos não são causados pelo Governo Municipal, pois pode-se constatar a sensibilidade e os esforços dos gestores em fazer valer os direitos das PCDs. O que fica evidenciado é a dificuldade do Governo Federal em fazer valer, na vida prática, o que preconiza as diferentes legislações, internacional e nacional, em prol de uma educação para todos, oportunizando direitos iguais e competência dos seus docentes.

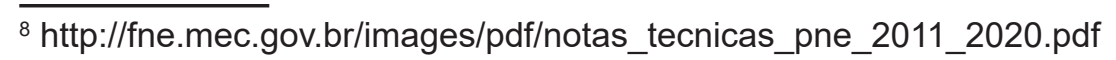


Este processo investigativo, por ter implicações práticas e, diante das suas conclusões, procurou-se de uma forma singela, informar e sensibilizar os gestores responsáveis pela SMECE e os educadores envolvidos, a irem em busca dos direitos das PCDs, em relação às esferas estadual e federal, fazendo valer o que preconiza a legislação vigente ao dar o amparo legal a esta população merecedora de recursos facilitadores durante a sua trajetória escolar, em seus ambientes domésticos, promovendo uma aprendizagem significativa, melhora nas relações pessoais, comunicação, autonomia e autoestima; uma maior capacitação inicial e contínua do corpo docente, titulares e de apoio; bem como, na temática inclusiva, com extensão à competência nas TICs.

\section{REFERÊNCIAS}

BOGDAN, R.; BIKLEN, S. Investigação qualitativa em educação: uma introdução à teoria e aos métodos. Porto: Porto Editora.

BRASIL. Plano Nacional de Educação- PNE. Aprovação do Nono Plano Nacional de Educação. 2011. Disponível em: http://fne.mec.gov.br/images/pdf/notas_tecnicas_ pne_2011_2020.pdf. Acesso em: 3/11/2020

CASARIN, M. M. O programa um computador por aluno (PROUCA) e a inclusão de alunos com deficiência. 2014. Tese de Doutorado, Universidade do Rio Grande do Sul, Brasil.

CONSELHO NACIONAL de EDUCAÇÃO. Resolução CNE/CP 1, de 18 de fevereiro de 2002. Institui Diretrizes Curriculares Nacionais para a Formação de Professores da Educação Básica, em nível superior, curso de licenciatura, de graduação plena. Disponível em portal.mec.gov.br/cne/arquivos/pdf/rcp01_02.pdf. Acesso em: 3/11/2020

GONÇALVES, J. R. As tecnologias de informação e comunicação como recurso à inclusão de crianças com necessidades educativas especiais. 2013. Tese de Doutorado, Escola Superior de Educação João de Deus, Lisboa, Portugal.

JONASSEN, D. Computadores, Ferramentas Cognitivas. Porto: Porto Editora. 2007. LEVY, P. Cibercultura. São Paulo: Ed. 34. 1999.

MARCHESI, Á.; MARTINE. Da Terminologia do distúrbio às necessidades educacionais especiais, In: COLL, C.; PALACIOS, J.; MARCHESI, Á. (orgs.). Desenvolvimento psicológico e educação. Necessidades educativas especiais e aprendizagem escolar. 1995. Porto Alegre: Artes Médicas.

MEC- Plano Nacional dos Direitos da Pessoa com Deficiência - Viver sem Limite, 
Decreto no. 7.612, 2011. Disponível em http://www.planalto.gov.br/ccivil_03/_ato20112014/2011/decreto/d7612.htm. Acesso em 3/11/2020

MENDES, G. L. Technology is the answer, but what was the question? About policies of technology insertion in schools and curricular change. European Journal of Curriculum Studies, Braga, 2(1), p. 233-244, 2015.

MONTEIRO DA CRUZ, M.; MONTEIRO, A. Acessibilidade cognitiva para o letramento de jovens com deficiência intelectual. Arquivos Analíticos de Políticas Educativas, Phoenix, 21(74), pp. 1-33, 2013.

MORAIS, A. M. M.; NEVES, I. P. Fazer investigação usando uma abordagem metodológica mista. Revista Portuguesa de Educação, Braga, 20(2),75-104, 2007.

NAÇÕES UNIDAS- Convenção dos Direitos da Criança. Adotada e proclamada pela Assembleia Geral das Nações Unidas em Carta Magna em 20 de novembro de 1989.

RODRIGUES, A. S. A informática como uma ferramenta de apoio à deficiência visual. Tese de Doutorado, Universidade do Rio Grande do Norte, Natal, Brasil. 2007.

RIBEIRO, J. E. M. As Tecnologias de Informação e Comunicação na Educação de Alunos com Necessidades Educativas Especiais: proposta de um Programa de Formação para o Ensino Básico. Tese de Doutorado, Universidade de Aveiro, Portugal. 2007.

SLEE, R. How do we make inclusive education happen when exclusion is a political predisposition? International Journal of Inclusive Education, Reino Unido, 17(8), p. 895-907, 2012.

TAVARES, M. R. N. Inclusão e prática pedagógica: dificuldades e desafios. Dissertação de Especialização Universidade do Rio Grande do Sul, Brasil. 2014.

TELES, R. F. O. Tecnologias para a inclusão: centros de recursos virtuais no apoio às necessidades educativas especiais. Portugal: Universidade do Minho, 2015

UNESCO. Declaração Universal dos Direitos Humanos. (1948). Representação da UNESCO no Brasil. Adotada e proclamada pela resolução 217 A (III) da Assembléia Geral das Nações Unidas em 10 de dezembro de 1948. UNICEF. The Right of Children with Disabilities to Education: ARights-Based Approach to Inclusive Education. Geneva: UNICEF Regional Office for Central and Eastern Europe and the Commonwealth of Independent States (CEECIS). 2012. 


\section{BIOGRAFIA DOS AUTORES}

SUZY DE ABREU COSTA - Graduada em Terapia Ocupacional pelo Centro Universitário Metodista- Instituto Porto Alegre, Porto Alegre, RS, Brasil. Especialista em Educação pelas Faculdades Integradas de Taquara, RS, Brasil. Mestre em Educação pela American World University, Latin American Division, United States of America-International Distance Learning, Doutoranda em Educação-Educação e Interculturalidade pela Universidade Aberta, Portugal, Lisboa. Fundadora e Diretora Geral da Helfen-Reabilitação Integrada desde 1991, Taquara, RS, Brasil. Fundadora e Diretora da Escola Especial Marcel Emílio Dani, Taquara, Rio Grande do Sul, Brasil. Integra o Grupo de Trabalho em Currículo e Equidade na Sociedade em Rede, LE@D, UAB.

FILIPA SEABRA - Doutora em Ciências da Educação, na área do conhecimento do Desenvolvimento Curricular pela Universidade do Minho, Mestre em Ciências da Educação pela Universidade Católica Portuguesa e Licenciada em Psicologia pela Universidade do Minho, Portugal. É Professora Auxiliar da Universidade Aberta, Portugal, desde 2010. É investigadora integrada do Laboratório de Educação a Distância e E-learning da Universidade Aberta, onde coordena o Grupo de Trabalho em Currículo e Equidade na Sociedade em Rede, e investigadora colaboradora do Centro de Investigação em Educação da Universidade do Minho e do Centro de Investigação em Psicologia da Música e Educação Musical (CIPEM/INET-Md).

Data de recebimento: 01/09/2020

Data de aprovação: 23/10/2020 